Recibido: 05-noviembre-2013

Aceptado: 15-noviembre-2013

\title{
LA TRASCENDENCIA DE LA NARRATIVA EN LA EDUCACIÓN INICIAL
}

SANDRA ELIZABETH PACHACAMA MAYORGA

Facultad de Filosofía, Letras y Ciencias de la Educación Universidad Central del Ecuador 


\section{RESUMEN}

La autora de este ensayo, analiza las consecuencias, tanto positivas como negativas, de la narrativa infantil en los pequeños. Descubre en esta narrativa una oportunidad genuina de aprendizaje. Frente a las fábulas, historias y cuentos infantiles, los párvulos aprenden a diferenciar entre personajes antagónicos.

Algo que vale la pena resaltar, es el rescate pedagógico de los cuentos de hadas, en contra de los criterios anacrónicos que veía en ellos algo negativo. Estudia a esta literatura como productora de inteligencia, sutileza, miedo, irreverencia, tristeza y, por supuesto, alegría.

La autora tiene muy clara la noción, de que al niño en edad preescolar no le interesa el análisis estilístico como tampoco la farragosa manera de contarlo.

Palabras clave: personajes, antagónicos, bien, mal, emoción, ímpetu, júbilo, análisis, estilística.

\section{ABSTRACT}

The author of this paper analyzes both positive and negative consequences of children's narrative fiction in children. It finds out in this narrative a genuine learning opportunity. It issues fables, stories and fairy tales, so toddlers learn to differentiate between antagonistic characters.

Something worth to mention, is the pedagogical rescue of fairy tales against the anachronistic criteria that show them something negative. Study this literature as a producer of intelligence, subtlety, fear, disrespect, sadness and of course, joy fulness.

The author has a very clear notion that the preschooler is not interested in stylistic analysis nor in the cumbersome way to tell.

Keywords: characters, antagonistic, good, bad, emotion, momentum, glee, analysis, stylistics. 
Antes de abordar el tema: La trascendencia de la narrativa en la educación inicial, es menester enfatizar en la forma como ha estado concebida la literatura en términos generales. Tradicionalmente la literatura ha sido abordada desde el asignaturismo, dándole un carácter histórico, desvinculándola de cualquier relación con el desarrollo de habilidades lingüísticas en el individuo. Esta afirmación se ve sustentada en la desvinculación con el pasado del ser humano, cuando olvidamos el contacto que tiene el individuo con la literatura en los primeros años de su vida; o cuando pasamos por alto el recordar que padres y maestros utilizaban canciones, retahílas, leyendas, poesía, cuentos, fábulas, o cualquier manifestación artística que haya conmovido las fibras más íntimas del niño; con el único fin de hacer que el aprendizaje del mundo inmediato de éste sea: activo, receptivo, productivo y funcional.

La presente ponencia tiene como objetivo fundamental destacar la importancia de la narrativa infantil como un hecho coyuntural en el desenvolvimiento integral de niños y niñas que atraviesan por el nivel inicial; nivel educativo que precisa despertar en el párvulo la fantasía y la sensibilidad a través de obras pertenecientes al género narrativo $y$, en los maestros la posibilidad de cultivar los valores, promover el espíritu de aventura, la investigación y el descubrimiento en el infante; en un ambiente de calidad y calidez compartido.

Sin embargo, somos testigos de cómo la literatura se hace cada vez más teorizante en la educación primaria y secundaria, provocando actitudes tediosas en los pequeños y jóvenes lectores; quienes no llegan a comprender cómo esas creaciones que un día le incitaban a imaginar, crear, reír y hasta llorar con sus contenidos, hoy sean mecanismos de tortura y represión. Esta realidad nos lleva a comprender que para el desarrollo de una competencia literaria se precisa de la correspondencia entre las habilidades lingüísticas (hablar, escuchar, leer, escribir) y el desarrollo de procesos cognitivos como: el análisis, la síntesis, la abstracción, la comparación, entre otros, sin dejar de lado el campo actitudinal del niño, con el único fin de despertar la sensibilidad y la búsqueda de placer imaginativo; con una visión amplia, activa y productiva, libre de prejuicios.

Cuando revisamos y comprendemos expresiones como: "lo más importante que encierran los libros en su corazón es la capacidad de cultivar"; ${ }^{1}$ nos hacemos eco de ese inescrutable mundo de maravillas infantiles que también fue nuestro y que muchos lo tenemos atizado en todo momento de la actividad docente como fuente viva y verdadera de conocimiento.

El art. 40 de la Ley Orgánica de Educación Intercultural (LOEI), del Ecuador, cita a la educación inicial como: "el acompañamiento del desarrollo integral que considera los aspectos cognitivo afectivo, psicomotriz, social, de identidad, y pertinencia a la comunidad y religión desde los tres años hasta los cinco años de

edad..."; ${ }^{2}$ bajo esta premisa se puede entender la necesidad de hacer de la narración un recurso sutil para el desarrollo de los propósitos que tiene la educación en este nivel; porque hablar de la trascendencia de la narrativa en la educación

\footnotetext{
${ }^{1}$ Hanan Díaz Fanuel, Leer y mirar el libro de texto, Colombia, Edit. Cargraphics S.A., 2007, p. 16.

${ }^{2}$ Ley Orgánica de Educación Intercultural (Loei), del 31 de marzo de 2011, Ecuador p. 85.
} 
inicial, es destacar el espíritu indómito del infante, es descifrar algunos escollos generados por la falta de consistencia en el manejo de las creaciones literarias como medio de expresión de pensamientos; es despertar los sentimientos y emociones; sin limitar la capacidad creativa de niños y niñas. Es facilitar la exteriorización de su mundo interno, permitiéndole una mejor socialización.

Considerar el enfoque práctico de la narrativa infantil como referencia de los hechos que afloran las vivencias de los párvulos a través de los personajes del texto narrativo; es determinar la correspondencia existente entre los actores de las diferentes historias y la realidad de nuestros pequeños lectores; estos sucesos identifican con mejor claridad muchos de los acontecimientos de la vida cotidiana del infante, constituyéndose en la fuente inagotable de argumentos que coadyuven a cumplir con los objetivos de la educación inicial.

El enajenamiento que provocan todas las historias, fábulas y cuentos infantiles producen una insólita reacción del niño frente al reconocimiento del mundo que le rodea. Esto no es casualidad, el ímpetu instintivo que desarrollan los párvulos, hace de la narrativa infantil una oportunidad de aprendizaje en donde, la presencia de personajes antagónicos le permite vislumbrar de mejor manera la diferencia del bien y el mal.

Ahora bien, el anacronismo con que se pretende estudiar la narrativa infantil al utilizar creaciones literarias como los tradicionales cuentos de hadas, hace suponer en muchas ocasiones, que existe incongruencia en la utilización de estas obras por considerarlas anticuadas, poco útiles para este tiempo, no dedicadas para niños, generadoras de violencia; sin embargo, no podemos perder de vista la capacidad que tienen estos cuentos para transmitir $y$ ejemplificar valores en el lector niño. Basta con dar un vistazo a décadas anteriores en donde estos mismos cuentos sirvieron de guía para alcanzar muchos de nuestros sueños.

La promoción de la narrativa infantil en los primeros años de escolaridad despierta la comprensión y el apego a las historias e incentiva el deseo por conocer nuevas e interesantes aventuras, nacidas en las acciones de cada personaje y experimentadas en las vivencias de cada niño. La accesibilidad que presentan las narraciones infantiles privilegia el desarrollo de la imaginación y la fantasía del infante en la recreación de las historias escuchadas; convirtiéndose la narrativa popular en un claro ejemplo de ese fenómeno social llamado folklore.

\section{El folklore en la literatura infantil ecuatoriana}

Cuando revisamos la etimología de la palabra folklore (Folk = pueblo y Lore $=$ acervo) encontramos que sus raíces, explican el acervo moral, cultural y material de una colectividad y la inventiva de un pueblo enmarcada en su historia y sus tradiciones. En concordancia a lo expresado podemos determinar que el folklore literario está constituido por todas aquellas composiciones, cuentos, leyendas, fábulas, construidas en el seno de los hogares y transmitidos a través de la oralidad de los adultos.

La corriente costumbrista de la literatura ecuatoriana refleja la importancia del folklore como fuente de la preservación de la riqueza cultural del pueblo, misma que constituye la mezcla de las etnias aboríge- 
nes, africanas, españolas, europeas, que testifican la presencia de un mestizaje totalmente integrado al territorio ecuatoriano. Si bien el tiempo narrativo constituye uno de los elementos más sobresalientes que permiten identificar una obra dentro del folklore de una colectividad, la época asegura la confiabilidad de los hechos porque consolida la actitud de su autor en respuesta al contexto cultural que promueve el comportamiento humano apuntando a fomentar los valores.

En síntesis, la cultura ecuatoriana es producto de la conquista más las tradiciones autóctonas ancestrales de pueblos precolombinos y aunque el folklore es ante todo oral, no impide que se transfiera al escrito como parte integrante de la literatura infantil; haciendo innegable el peso que el folklore popular mantiene en las diversas composiciones de destacados autores como: Hernán Rodríguez Castelo, de quién Antonio Orlando Rodríguez (1955) en la obra Panorama histórico de la literatura infantil, manifiesta: "En su obra, de prosa tersa y vehemente, de connotaciones parabólicas y profundo cimiento filosófico (...), late siempre un sustrato de belleza, solidaridad, y una aspiración de confirmar al niño la posibilidad de soñar". Antonio Rodríguez no deja de concebir "la esperanza como substancia de lo humano y promesa de arribo final a un mundo en que el hombre sea realmente hombre, en una sociedad pacífica y solidaria, plenamente humana". ${ }^{3}$

En los actuales momentos la narrativa ecuatoriana infantil está caracterizado por manifestaciones que reflejan historias cotidianas y fantásticas que promueven un

\footnotetext{
${ }^{3}$ Antonio Orlando Rodríguez, Panorama histórico de la literatura infantil, Bogotá, CERLALC, 1994, p. 139.
}

fehaciente ingenio estético, creativo de autores y autoras que exponen su producción atendiendo a dimensiones psicológicas y emocionales que discurren en la relación que llegan a mantener personajes y lectores; este hecho ha posibilitado la formación de la personalidad del ser humano dotado de ubicación, pertenencia y afinidad, así como confiere a la persona sensibilidad y conciencia individual y colectiva.

Darío Guevara (1955) afirma: "La tradición es un sustento respetable, raíz de la existencia de los pueblos, cariñosa presencia del pasado; pero el mundo sin alzarse de hombros a lo que fue y se conserva en herencia colectiva, está marcando el presente y preparando el porvenir". ${ }^{4}$ De lo mencionado podemos deducir que el folklore es una fuente importante de la literatura y la expresión estética de la cultura nacional que reclama su sitio en el presente de los ciudadanos de cada patria.

Las primeras narraciones que escuchará el niño son historias relacionadas con su medio, mismas que se convertirán en su acervo cultural. Cuando comprendamos que la aplicación de la narrativa infantil tiene su inicio en la orilla de una cuna, cuando papá o mamá, y en ocasiones ambos, cuentas historias llenas de encanto a sus hijos antes de dormir; estamos desarrollando la tradición oral; y, más tarde, cuando la educación inicial entra en acción, es el maestro el promotor y ejecutor de esta asombrosa tarea de narrar aventuras para niños a través de la lectura en voz alta; despertando en ellos la emoción, el entusiasmo, el placer por la narraciones escuchadas y el genuino interés por conocer cada día más.

\footnotetext{
${ }^{4}$ Psicopatología y psicopedagogía del cuento infantil, Quito, Casa de la Cultura Ecuatoriana, p. 131 .
} 
Es entonces, cuando con beneplácito tomamos como referencia las palabras de Ramón Torrijos, María del Mar cuando manifiesta que: "la vinculación existente entre cuento popular y folclore nos permite afirmar que: "es precisamente del folklore, de donde hemos de partir, como de un manantial inicial, si queremos descubrir el significado y la función de la literatura para la niñez" (Medina, 1990, p. 37). Recuperado el 2 de abril del 2013 http://webs.ono.com/garoza/G5ramontorr ijos.htm

Por ello, se precisa observar que la narración oral actúa como el cimiento que mantiene la cultura de los pueblos, esa cultura que nace en las historias populares, en las leyendas, en los mitos, en las tradiciones y que está guardada en el baúl de los recuerdos, de todo individuo, que pasa a constituir su bagaje de experiencias. Posteriormente la narrativa propuesta en el texto escrito, marca el punto de partida en el proceso de aprendizaje en la educación inicial; porque, llega a instaurar el paradigma de la tradición ancestral del infante y el contacto con todas esas historias verosímiles o inverosímiles conformarán la añoranza de sus próximas etapas de vida.

Por todo lo expuesto, es menester considerar que las obras literarias traen consigo una serie de matices como: la inteligencia, la sutileza, el miedo, la irreverencia, la tristeza, la alegría, entre otros; representando así, las múltiples experiencias de los seres humanos; dándole ciertas claves al lector para enriquecer su mundo interior y construir las diversas circunstancias de los personajes sin deformar su propia realidad.

Debemos comprender que al niño en edad preescolar no le interesa el análisis estilísti- co de una obra infantil, ni la farragosa manera de contarla. El infante da mayor importancia al ímpetu jubiloso de quien narra las proezas de los héroes (príncipes, princesas, ogros, dragones) que aparecen en las historias; y, la emotividad aplicada en la narración es el eje preponderante para que un hecho contado permanezca en la memoria y no desaparezca de ella como un acontecimiento efímero y pueril, que muchos podrían catalogarla como una circunstancia propia de la edad.

Comprender la naturaleza del tema en la narración infantil, puede facilitar el concurso de ideas que aporten a entender la importancia del uso de ésta en la educación inicial. Por otra parte, inconscientemente en el niño se va almacenando el hilo argumental de la historia escuchada o leída y empieza a emanar en él esa experiencia que se transforma en la mejor síntesis del cuento y el asidero de esos posibles detalles que recordará el infante en el transcurso de su vida.

Lograr que el hecho narrativo inicie y se mantenga como la base trascendental de la actividad lectora, en los párvulos, es deber de padres y maestros; así, evitaremos que ésta se haga extenuante en los próximos años de estudio de los potenciales lectores.

$\mathrm{Si}$ indagamos en los confines de nuestra memoria, seguramente descubramos que la mayoría de los valores firmemente arraigados en nuestra propia personalidad; provienen del contenido de algún cuento que dejó una enseñanza imperecedera y que no pasó fugazmente en nuestra existencia. Así como muchos niños y niñas pueden reconocer en los personajes de las obras infantiles sus propias acciones; así reconoce el maestro la funcionalidad de la narrativa en cada grupo de niños. En sínte- 
sis podríamos decir que, "Los tres cerditos", pudieron inculcar la importancia de trabajar bien; mientras, Caperucita es solidaria con un adulto mayor que tiene su salud quebrantada, o, Pinocho que solo quiere ser un niño de verdad; y, la constancia y modestia manejada por la tortuga, en la fábula "la liebre y la tortuga", confirma la sutil trascendencia educativa que tiene la narrativa en el educación inicial.

Por ello, es de vital importancia que padres y maestros dediquen más tiempo a la narrativa que estimule al infante al reconocimiento de su propia historia; estableciendo, en ella, las buenas prácticas sociales, experiencias que estimulan la imaginación, la fantasía y la posibilidad de crear las más nuevas y fascinantes aventuras germinadas en el interior de su mundo $y$ proyectadas en sus más simples y excitantes acciones.

\section{Desafíos de la actual narrativa infantil ecuatoriana}

El desafío propuesto por la narrativa infantil ecuatoriana, no dista de las expectativas planteadas por países que tienen cierto grado de similitud con el nuestro; principalmente con aquellas que tienen que ver con la concepción de infancia desde la óptica de los instituciones internacionales como: la Organización de las Naciones Unidas para la Educación y la Cultura (UNESCO), y el Fondo de las Naciones Unidas para la Infancia (UNICEF); Las instituciones concentradas en el marco del Congreso de Colombia definieron a la educación como: "un proceso de formación permanente, personal, cultural y social que se fundamenta en una concepción integral de la persona humana, de su dignidad, de sus derechos, $y$ de sus deberes". ${ }^{5}$

En correspondencia a lo expuesto, toda la producción literaria infantil enfrenta una gran responsabilidad ante los pequeños lectores, como conocer las características evolutivas de la edad y los derechos consignados en la Constitución de cada uno de sus países.

En Ecuador, uno de los objetivos institucionales del Ministerio de Educación en lo concerniente a la educación inicial es: "Potenciar el aprendizaje y promover el bienestar, de niños y niñas menores de cinco años, mediante experiencias significativas y oportunas que se dan en ambientes estimulantes, saludables y seguros". ${ }^{6}$

Sus expectativas se afianzan en la vigencia del Reglamento a la Ley Educación Orgánica de Educación Intercultural, (Art.27) en el cual encontramos al nivel de Educación Inicial dividido en dos subniveles: a) Inicial 1 , no es escolarizado y comprende a infantes de hasta tres años de edad; b) Inicial 2, que comprende a infantes de tres a cinco años de edad. Este marco jurídico pone en manos del maestro, promover ambientes de confianza, respeto y responsabilidad en su grupo de infantes, para ello el docente hace suya la literatura infantil, especialmente la narrativa, como el recurso didáctico idóneo que tiene la educación inicial para lograr que los aprendizajes de los párvulos sean significativos y oportunos.

\footnotetext{
${ }^{5}$ Ley 115 de 1994. Decreto del Congreso de Colombia, por el cual se expide la Ley General de Educación, recuperado el 20 de marzo de 2013.

${ }^{6}$ Web site Ministerio de Educación del Ecuador, recuperado 20 de marzo del 2012.
} 
La compilación profunda de textos narrativos permiten al lector adulto reconocer, que el autor de literatura infantil, no escribe únicamente para impresionar al lector niño; ni para sustentar su imagen en su entorno de escritores; el escritor infantil actual se preocupa de las características evolutivas del niño y se propone nuevos desafíos que deben responder con mayor eficacia a las necesidades lectoras infantiles. Como son : a) sus intereses egocéntricos, b) sus momentos breves de atención, mismos que se van incrementando conforme continua su edad cronológica, c) su necesidad de conocer y reconocer el mundo y los seres que lo habitan, d) su capacidad de impresionarse, e) su tierna sensibilidad, f) su responsabilidad ante las acciones, g) su espíritu aventurero. En fin, el abordaje de los desafíos citados, no se compara con la agudeza que debe manejar el autor en el tratamiento temas de actualidad que afectan emocional y psicológicamente a niños y niñas como son: la migración, la desestabilización familiar, la pobreza, el alcoholismo, la delincuencia juvenil, la ecología, entre otros.

Todo desafío debe ir encaminado a la interacción entre los actores de la educación, lo que dará paso a la versatilidad en la utilización de recursos en especial a lo que tiene que ver con la producción literaria constituyéndose en una puerta abierta al mundo real del infante y a la oportunidad de provocar el deleite estético desde una perspectiva más significativa para el desarrollo integral de niños y niñas.

\section{Antología de narrativa infantil ecuatoriana}

La promoción de la literatura infantil ecuatoriana responde al accionar de algunas instituciones de origen privado y público; que, desde hace un tiempo atrás se han preocupado por difundir trabajos de autores y autoras, cuya destreza narrativa les ha permitido alcanzar reconocimientos nacionales e internacionales consagrándolos como personajes importantes en la antología literaria infantil.

Francisco Delgado Santos, en respuesta a la solicitud del Gobierno de la Provincia de Pichincha y su Programa Edufuturo; hace una clasificación de los escritores, hombres y mujeres, destacados en la narrativa infantil, atendiendo en primer lugar a los precursores de este género literario en el país; así tenemos a: "Teresa Crespo de Salvador, Hernán Rodríguez Castelo y Alfonso Barrera Valverde".

En segundo lugar ubica a los galardonados del Premio Darío Guevara del Municipio de Quito, aquí tenemos a: "Ana Catalina Burbano, Edgar Allan García, María Fernanda Heredia, Francisco Delgado, Eliécer Cárdenas, Soledad Fernández de Córdova y Edna Iturralde".

$Y$ en tercer lugar ubica a aquellos escritores que han publicado interesantes muestras de su arte como: Elsa María Crespo, y Raquel Rodas.

El amplio sumario que hace Francisco Delgado Santos es vital para la historia de la narrativa infantil ecuatoriana; sin embargo, en los últimos años este listado se ha incrementado con la presencia autores que buscan satisfacer el recóndito mundo del infante y a pesar que para muchos, la narrativa infantil pasa desapercibida, para los pequeños lectores la narrativa infantil va ganando un espacio importante en su vida; porque, en múltiples ocasiones las historias contadas identifican al niño lector con alguno de los personajes propuestos en las historias narradas. 
El primer reto al que se somete toda producción dirigida al infante tiene que ver con la exquisitez que debe manejar el autor en su rol de creador de la obra; lo que le encamina a cautivar, divertir, despertar el interés por el hecho narrado y por ende avivar el deseo de los párvulos por aprender a leer. La perspicacia en el manejo del lenguaje, en la narración para niños, asegura el desarrollo de la imaginación, la puesta en juego del inquebrantable espíritu inquieto del niño y la superación de sus miedos y sus sueños más íntimos.

Algunos autores y autoras nos privilegian con sus creaciones, que son la muestra fehaciente de que en Ecuador se ha dado pasos gigantescos en la producción literaria infantil. Así podemos contar con Ana Carlota González y su creación "Alicia y los dientes"; en la que a través de una historia humorística, el personaje niño aprende el valor del respeto y la paciencia ante cualquier circunstancia de la vida.

El Día que el Sangay se convirtió en Volcán, obra de María Eugenia Lasso, busca destacar la temática de la identidad enfatizando en los valores de solidaridad y autoestima, sin dejar de lado la descripción de los hermosos paisajes naturales y de la cultura ecuatoriana.

Otras producciones que por justicia tienen que ser presentados como obras ejemplares de la literatura infantil ecuatoriana son:

Leer en la cama, escrita por Soledad Córdova. Es la historia de dos niños, Hannah y María Emilia que buscan acceder a sus historias favoritas transformando la repisa de los libros en camas para así disfrutar mejor de una siesta.
La autora María Cristina Aparicio pretende con el contenido de su historia: "Un Monstruo Se Comió La Nariz", reconocer la importancia de las cosas simples, como disfrutar del sol y tener sueños, y valorar la función que tiene el sentido del olfato para su protagonista.

"La bicicleta verde limón", de Elsa María Crespo transporta al niño, a poner en práctica sus talentos y a ubicar los límites donde su mente y corazón decida; además le invita a pensar cuan necesario son los amigos en momentos difíciles, especialmente para superar los miedos.

Edna Iturralde, es una escritora fascinante, hace de cada una de sus historias un derroche de sentimientos; en su obra: "Un país llamado Ecuador" pone énfasis en el fomento e identidad de tradiciones ecuatorianas, es una obra para niños emigrantes para que recuerden a su Patria y compartan su cultura; Y cómo olvidar a "TorbeIlino", un caballito que a su muerte, nos enseña el desapego de los seres querido cuando estos han cumplido con su ciclo de vida.

Francisco Delgado Santos, en su obra "Tener una familia" lleva de la mano al niño, de una manera muy gráfica, comparando la primera célula social con el paraguas que nos cubre de la lluvia, o un leño que nos calienta en invierno, o el agua fresca que quita la sed en verano, el refugio, la caricia, el hombro amigo, la mano abierta, los padres, hermanos, tíos y mascotas que siempre te hacen sonreír. Con su mundo desbordante de amor permite extraer del mismo niño el significado de una familia.

En síntesis los autores contemporáneos, como: Edna Iturralde, María Fernanda, Heredia, Édgar Allan García, Leonor Bravo, 
Alicia Yánez Cossío, Ana González de Soria, entre otros, coinciden en enfocar la literatura infantil desde una perspectiva de servicio a los demás, el rescate de valores y la consolidación y difusión de la literatura infantil ecuatoriana en el nivel educativo más vulnerable, sensible; pero, el más asombrosos, como es la educación inicial.

La mayor parte de los autores citados están organizados en la Asociación de Escritores e llustradores de Literatura Infantil y Juvenil del Ecuador denominada Girándula; y $\sin$ temor a equivocarnos podemos afirmar que los ecuatorianos estamos orgullosos de la producción narrativa infantil, porque ella constituye: a) la irradiación y el compromiso étnico y humano, que le llevan al niño a construir mundos mágicos e insospechados; b) el acercamiento a las puertas de su alma despertándolos a una realidad más justa, honesta y sencilla, sin ningún tipo de manipulación propendiendo al rescate de valores; c) la creación de un mundo de fascinación y entretenimiento; d) el vivir a profundidad la historia para que resulte creíble y tenga vida propia; e) el rescate de la cultura y la tradición; f) formar niños lectores con amplia capacidad crítica; y, g) la posibilidad de abordar temas en los que se destierre la violencia y se introduzca la bondad y la ternura como una alternativa para una época, socialmente, tan convulsionada como la actual.

\section{Más argumentos a la utilización de la narrativa}

La trascendencia de la literatura en la educación inicial se resume en la capacidad que tienen estas dos variables, narrativa y educación inicial, para fusionarse en la búsqueda del verdadero propósito de la educación: el cultivar el pensamiento libre, sin miedos ni tabúes, que le permita dis- cernir, por sí mismos, lo real de lo ficticio y comprender que el mejor referente de la vida es la libertad de vivir; aplicando como recurso didáctico las obras narrativas que motiven en el infante el interés por conocer su mundo a través de la lectura.

Una eficiente narración, fácilmente se convierte en un medio de expresión significativa de ideas, pensamientos y sentimientos de quien la escucha; debido a que el interés que mueve el contenido de las historias aviva el poder creativo del niño, en los primeros años de vida, y proyecta nuevos objetivos comunicativos y estéticos. El lenguaje familiar que posee la narración atrapa de tal manera la atención del infante que en forma imperceptible empieza a socializar con su grupo escolar.

Cassany Daniel (2008) manifiesta: "La cultura en sentido amplio impregna muchos detalles de la vida cotidiana (...) y en el aula hacemos y reproducimos cultura constantemente" ${ }^{77}$ (p. 553).

Es precisamente en esa vida de aula, que el párvulo intenta descifrar el mundo que le rodea y todas las respuestas que va obteniendo se impregnan en los rasgos de la cultura. Cuando el niño en su acto imaginativo inmediato y en afán de descubrir encuentra que, el portador de todas esas nuevas experiencias es el libro; es cuando el ingenio de la narrativa se ve puesta a prueba; debido a que las particularidades del texto, carátula, títulos, ilustraciones, páginas, deben ser revisadas frecuentemente para brindar a los niños nuevos temas que atrapen su interés. Hay que señalar que todas las propuestas narrativas contienen una trama, hechos, personajes, espacios, tiempos problemas y solucio-

\footnotetext{
7 Daniel Cassany, Enseñar Lengua, España
} Edit. GRAO, 2008. 
nes que el niño puede relacionarlos con otras historia leídas o con sus propias vivencias; por ello, la necesidad de desarrollar la originalidad en la narrativa.

Es inevitable recalcar que el hábito lector nace en la infancia y con la sutil perspicacia del maestro que bien haga su labor; logrará que el niño se convierta en un crítico lector de libre pensamiento; cumpliendo sin duda alguna el objetivo de la narración en la educación inicial.

\section{BIBLIOGRAFÍA}

CASSANY, Daniel (2008). Enseñar Lengua, España, Edit. GRAO.

GUEVARA, Darío. Psicopatología y psicopedagogía del cuento infantil, Quito- Ecuador, Casa de la Cultura Ecuatoriana, p. 131.

HANAN DÍAZ, Fanuel (2007). Leer y mirar el libro de texto, Colombia, Edit. Cargraphics S.A., p. 16.

Ley Orgánica de Educación Intercultural (LOEI), del 31 de marzo del 2011, Ecuador.

Reglamento a la Ley Orgánica de Educación Intercultural (R-LOEI), Ecuador, del 26 de julio del 2012.

RODRÍGUEZ Antonio Orlando, (1994). Panorama histórico de la literatura infantil, Bogotá, CERLAC.

\section{FUENTES ELECTRÓNICAS}

http://www.secretariasenado.gov.co/sena do/basedoc/ley/1994/ley 0115 1994.html recuperado 02 de abril del 2012.

http://www.educacion.gob.ec/index.php/e ducacion-inicial-eei recuperado el 02 de abril del 2012. 